\title{
Visualising E-selectin in the detection and evaluation of inflammatory bowel disease
}

\author{
M Bhatti, P Chapman, M Peters, D Haskard, H J F Hodgson
}

\begin{abstract}
Background-Vascular endothelial Eselectin expression is induced by proinflammatory cytokines and contributes to accumulation of leucocytes in tissues. Aims-To investigate the role of E-selectin in inflammatory bowel disease (IBD).

Methods-E-selectin expression was assessed in patients with ulcerative colitis and Crohn's disease by measuring the concentration of circulating soluble E-selectin (sE-selectin) using ELISA, by immunohistochemistry of colonic biopsy specimens, and by abdominal immunoscintigraphy after injecting radiolabelled $\mathbf{F}\left(\mathbf{a b}^{\prime}\right)_{2}$ fragment of a monoclonal anti-Eselectin antibody. The value of scintigraphy using anti-E-selectin was judged by a prospective comparative study of autologous leucocyte scanning and E-selectin antibody scanning in 17 patients with IBD. Results-Circulating sE-selectin was elevated in patients with clinically active disease. Tissue expression of E-selectin was enhanced in patients with active inflammation, with weak or absent expression in inactive disease and healthy controls. In-111 labelled anti-E-selectin scintiscans were compared with Tc-99m labelled leucocyte scans performed 24 hours earlier. Twelve patients had areas of active inflammation on leucocyte scan while 11 patients had positive E-selectin scans. The results of the two scans were concordant in 14 patients, with those positive for both $(10 / 17)$ showing similar disease localisation and extent.

Conclusions-Tissue E-selectin and circulating sE-selectin are increased during active inflammatory bowel disease. AntiE-selectin imaging with radiolabelled monoclonal antibody identified areas of inflammation in Crohn's disease and ulcerative colitis. The technique should prove useful clinically for identifying the site and extent of disease.

(Gut 1998;43:40-47)
\end{abstract}

Keywords: E-selectin; inflammatory bowel disease; Crohn's disease; ulcerative colitis

The vascular endothelium is an active participant in inflammatory processes. The response of endothelial cells to a variety of proinflammatory stimuli includes synthesis and expression of a number of cell surface antigens, ${ }^{1}$ many of which are also released into the bloodstream. E-selectin is a $115 \mathrm{kDa}$ glycoprotein which is expressed on the luminal surface of endothelial cells in response to proinflammatory cytokines such as interleukin 1 (IL-1) and tumour necrosis factor (TNF), or bacterial lipopolysaccharide, and plays a major role in facilitating the emigration of leucocytes into the tissues. ${ }^{2-4}$

Accumulation of polymorphonuclear leucocytes from the circulation into the gut wall is an integral component of the inflammatory process in the chronic inflammatory bowel diseases (IBD), ulcerative colitis, and Crohn's disease. E-selectin expression has been shown immunohistochemically in areas of active involvement of the gut. ${ }^{5-8}$ As expression of E-selectin is limited to activated endothelium, ${ }^{9}{ }^{10}$ this molecule provides a potential target for in vivo detection and quantitation of disease activity.

Recent studies using animal models of inflammation have shown that intravenously injected radiolabelled anti-E-selectin monoclonal antibody is specifically taken up by activated endothelium, and that the degree of uptake can provide a quantitative measurement of E-selectin expression. ${ }^{112}$ Murine anti-Eselectin monoclonal antibody 1.2B6, labelled with In-111, can be used to image E-selectin expression, both in models of monoarthritis ${ }^{13-15}$ and in patients with rheumatoid arthritis, ${ }^{16}$ the specificity of anti-E-selectin uptake being shown by significantly more focal and intense images compared with those obtained with radiolabelled control IgG.

In this study we have explored the potential of this simple technique to image inflamed intestine in IBD. We have also confirmed E-selectin up regulation in ulcerative colitis and Crohn's disease by measuring soluble E-selectin levels ${ }^{17}{ }^{18}$ in the circulation and by detection of E-selectin expression immunohistologically in intestinal biopsy specimens.

\section{Materials and methods}

PATIENTS AND CONTROLS

For circulating soluble E-selectin, three groups were investigated: group I, Crohn's disease (CD; 16 patients; nine men and seven women; median age 42.5 years, range $21-65$ ); group II, ulcerative colitis (UC; 16 patients; eight men and eight women; median age 38 years, range 20-79); group III, controls (11 healthy volunteers; seven men and four women; median age 33 years, range $18-68$ ). For imaging with monoclonal anti-E-selectin antibody two groups, both with active IBD, were investigated: group I, CD (seven patients; four men and three women; median age 33 years, range 21-51); group II, UC (10 patients; six men and four women; median age 38.5 years, range 22-79).

The diagnosis of UC and CD was based on clinical, radiological, endoscopic, and biopsy findings. Approval for the study was obtained from the Hammersmith Hospitals Trust 
Research Ethics Committee and the Administration of Radioactive Substances Advisory Committee (ARSAC). Each patient gave informed consent to participate in the study.

DISEASE ACTIVITY

Crohn's disease activity was assessed by the Crohn's Disease Activity Index (CDAI $)^{19}$ which assesses eight clinical variables. Remission was defined by a score of less than 150 and severe illness by a score of more than 450 . The patients with ulcerative colitis were clinically assessed as being in remission or having mild, moderate, or severe disease, as described by Truelove and Witts. ${ }^{20}$

MONOCLONAL ANTIBODY LABELLING WITH ${ }^{111}$ In $1.2 \mathrm{~B} 6$ is a mouse IgG1 monoclonal antibody and recognises porcine and human E-selectin. ${ }^{21}$ The $\mathrm{F}\left(\mathrm{ab}^{\prime}\right)_{2}$ fragment was produced by pepsin digestion of the whole antibody and further purified by protein A affinity chromatography and dialysis. The purity of $\mathrm{F}\left(\mathrm{ab} \mathrm{b}^{\prime}\right)_{2}$ was assessed by non-reducing sodium dodecyl sulphate-polyacrylamide gel electrophoresis, and a single band was identified. The immunoreactivity of $\mathrm{F}\left(\mathrm{ab}^{\prime}\right)_{2}$ was confirmed by enzyme linked immunosorbent assay (ELISA) on cultured endothelial cells.

Antibodies were labelled with ${ }^{111}$ In using the method of Danpure et al. ${ }^{22}$ The $\mathrm{F}\left(\mathrm{ab}^{\prime}\right)_{2}$ was coupled with diethylenetriaminepentaacetic acid (DTPA) bicyclic anhydride (Sigma Chemical Co, Dorset, UK) at $\mathrm{pH}$ 8.0, pooled, filtered through a $2 \mu \mathrm{m}$ microfilter (Ministart, Sartorius $\mathrm{GmbH}$, Gottingen, Germany) and stored at $4^{\circ} \mathrm{C}$ in $20 \mu \mathrm{l}$ aliquots. On the day of the experiment, 20-25 MBq of carrier free ${ }^{111}$ In chloride (Amersham International, Amersham, UK) was brought to $\mathrm{pH} 6.0$ by addition of $45 \mu \mathrm{l}$ of $3.8 \%$ sodium citrate, $\mathrm{pH} 7.4$, and was added to a $20 \mu \mathrm{l}$ $(1 \mathrm{mg} / \mathrm{ml})$ aliquot of antibody. After 30 minutes at room temperature, free ${ }^{111}$ In was removed by passage through a Sephadex G50 column. The radiopharmaceutical purity, assessed using thin layer chromatography on silica gel (ITLC-SG; Gelman Sciences, Ann Arbor, Michigan, USA) with phosphate buffered saline (PBS) solution as the solvent, was $98.4(1.4) \%$. The injected dose was 12.4 (1) MBq.

LEUCOCYTE LABELLING WITH ${ }^{99 \mathrm{~m}} \mathrm{Tc}$

Autologous polymorphonuclear leucocytes (PMN) were separated from $96 \mathrm{ml}$ of venous blood and labelled with Tc-99m hexamethylpropyleneamine oxime (HMPAO; hexametazime (CERETEC); Amersham International, UK), using a modification of the method of Danpure et al. ${ }^{22}$ The blood was drawn in two 60 $\mathrm{ml}$ syringes containing $10 \mathrm{ml}$ of acid citrate dextrose (ACD; National Institute of Health formula A). ACD mixed blood $(40 \mathrm{ml})$ was centrifuged at $3000 \mathrm{rpm}$ for 15 minutes to obtain cell free plasma for washing and resuspension of labelled white cells. Remaining ACD-blood was mixed with hydroxyethyl starch (Hespan, $6 \%$ in saline solution; Dupont Pharm, Letchworth, UK) and was left for about one hour at room temperature. Leucocyte rich, platelet rich supernatant was removed and centrifuged for five minutes at $150 \mathrm{~g}$ to obtain a pellet containing leucocytes. Leucocytes were labelled using 250 $\mathrm{MBq}$ of freshly prepared ${ }^{99 \mathrm{~m}} \mathrm{Tc}$ HMPAO. The labelled PMNs were washed and suspended in 5 $\mathrm{ml}$ of cell free plasma. The mean labelling efficiency was $75 \%$ and the injected dose was 170 (15) MBq. The number of PMN injected was $1.4 \times 10^{8}$ and the cell purity was more than $90 \%$ with less than $4 \%$ non-viable cells, as assessed by trypan blue and ethidium bromide/ acridine orange stain in PBS.

\section{IMAGING}

Anterior, posterior, and pelvic outlet images were obtained one, four, and 24 hours after intravenous injection of ${ }^{99 \mathrm{~m}} \mathrm{Tc}$ labelled leucocytes, using a gammacamera equipped with a low energy, general purpose collimator. ${ }^{111}$ In labelled anti-E-selectin monoclonal antibody was administered 24 hours after the ${ }^{99 \mathrm{~m}}$ Tc leucocyte injection and images were obtained using a medium energy collimator at one, four, and 24 hours and in some cases 48 hours postinjection.

EVALUATION OF IMAGES

Images were evaluated without knowledge of clinical data by experienced nuclear medicine physicians. The distribution of uptake of anti-E-selectin was compared with that of ${ }^{99 \mathrm{~m}} \mathrm{Tc}$ PMN. For the localisation of disease activity with labelled PMN, intestinal segments were considered pathological when labelled PMN showed abnormal localisation at one hour, and PMN imaging at 24 hours was used to outline the colon but not for diagnostic purposes. In the case of ${ }^{111}$ In labelled anti-E-selectin, intestinal localisation at any time (four, 24, 48 hours) was considered abnormal.

ASSAY OF SOLUBLE E SELECTIN

Acid citrate dextrose containing venous blood $(5 \mathrm{ml})$ was centrifuged at $3000 \mathrm{rpm}$ for 15 minutes to isolate cell free plasma. Quantitative estimation of soluble E-selectin was performed in triplicate using sandwich ELISA. ${ }^{18}$ Briefly, 96 well polyvinyl plates (Greiner, UK; 655061) were coated with monoclonal mouse antihuman antibody and were kept overnight at $4^{\circ} \mathrm{C}$. The next morning plates were washed multiple times and blocked with $1 \%$ bovine serum albumin for two hours at $37^{\circ} \mathrm{C}$. Plates were then incubated with plasma and multiple dilutions of known amounts of E-selectin (later used to plot a standard curve to quantitate samples) at $37^{\circ} \mathrm{C}$ for two hours. After multiple washes plates were again incubated at $37^{\circ} \mathrm{C}$ with biotinylated mouse antihuman monoclonal antibody. Two hours later plates were washed and incubated with peroxidase conjugated reagents A\&B (Sigma, UK) for one hour at room temperature. After further washes plates were developed with orthophenylenediamine and the reaction was stopped with $2 \mathrm{M} \mathrm{H}_{2} \mathrm{SO}_{4}$. Colour intensity was measured using an ELISA reader at $492 \mathrm{~nm}$. 


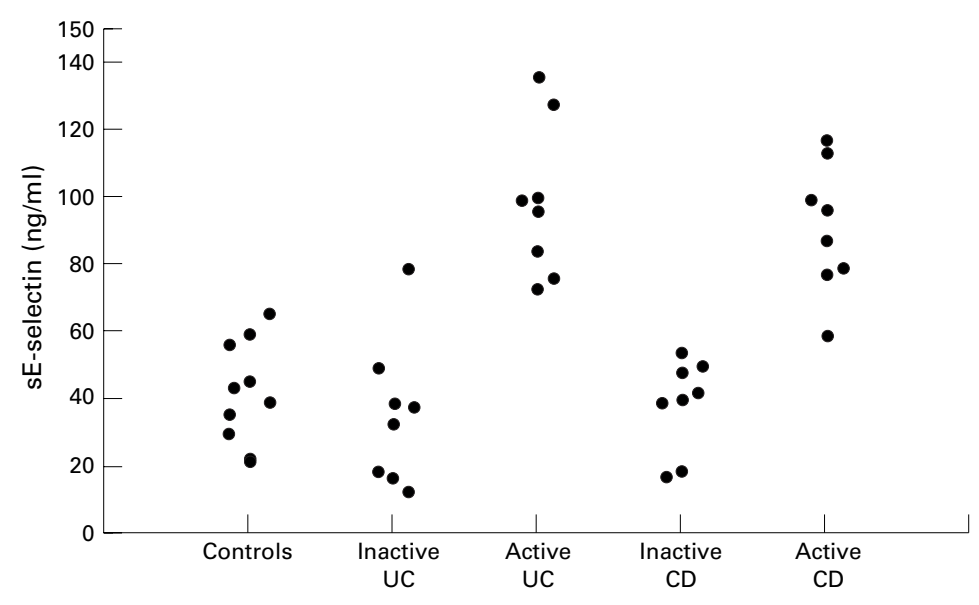

Figure 1 Levels of circulating sE-selectin in active and inactive IBD, and controls (healthy volunteers). CD, Crohn's disease; UC, ulcerative colitis.

IMMUNOHISTOLOGICAL ASSESSMENT OF BIOPSY SPECIMENS

Cryostat sections of biopsy samples from colon and small intestine were immunostained using a modified peroxidase method. ${ }^{23}$ Briefly, $5 \mu \mathrm{m}$ thick frozen sections were cut by cryostat and air dried for at least one hour. Sections were fixed in acetone and endogenous peroxidase activity was blocked by $\mathrm{H}_{2} \mathrm{O}_{2}$. Monoclonal anti-E-selectin antibody was added to the sections in a humid chamber and kept at $4^{\circ} \mathrm{C}$ overnight. This was followed by polyclonal sheep antimouse peroxidase conjugated antibody for one hour at room temperature. After this slides were immersed in 3,3-diaminobenzidine solution for 15 minutes, washed, immersed in haematoxylin for one minute, washed, dehydrated and cleaned before mounting coverslips. Sections were washed with PBS two to three times after each step. The degree of inflammation and the intensity of E-selectin expression in tissue sections was scored by an experienced observer blinded to the clinical diagnosis of patients. A semiquantitative scale of 0 (no detectable staining), + (weak staining of occasional vessels), ++ (widespread moderately stained vessels), +++ (widespread strongly stained vessels) was used. A similar semiquantitative analysis was used for the extent

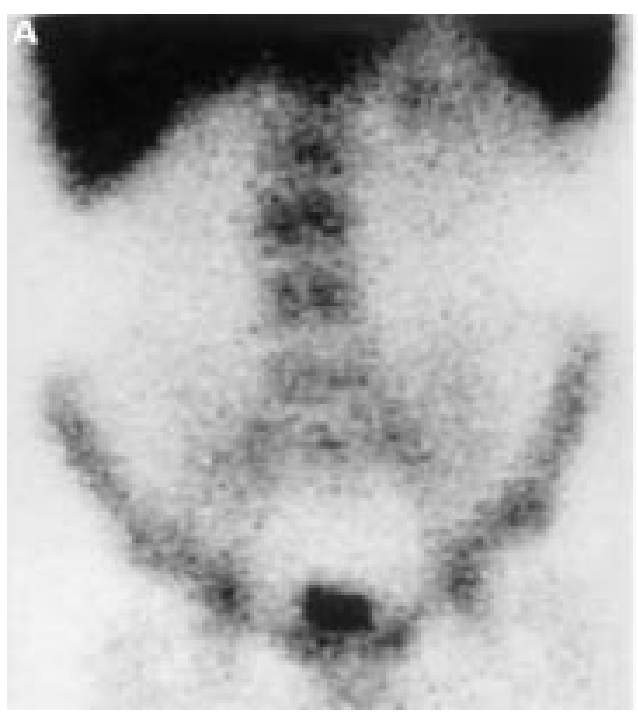

Figure 2 Negative images. $(A){ }^{99 m}$ Tc leucocyte scan; (B) ${ }^{111}$ In labelled anti-E-selectin scan. of polymorphonuclear leucocyte infiltration in the lamina propria of the mucosa.

\section{STATISTICS}

The Mann-Whitney U test was used to assess the differences between patient groups. Simple linear regression and Pearson's product moment correlation were used to identify the relation of variables with disease activity as determined by the CDAI and Truelove and Witts' criteria. ${ }^{19}{ }^{20}$

\section{Results}

CIRCULATING SOLUBLE E SELECTIN

sE-selectin was measured in peripheral blood of 43 individuals (fig 1). sE-selectin values in the serum of 11 healthy donors ranged from 18 to $53 \mathrm{ng} / \mathrm{ml}$ (mean (SD) 41 (14) $\mathrm{ng} / \mathrm{ml}$ ). Values were redetermined at three months in six volunteers and did not show any statistically significant variation. The serum levels of sE-selectin of patients with inactive UC (eight patients) and CD (eight patients) did not differ significantly from normal (37 (21) and 35 (13) ng/ml respectively). However, in both active UC (eight patients) and CD (eight patients) there were significantly elevated levels of sE-selectin (98 (22) and 89 (16) $\mathrm{ng} / \mathrm{ml}$ respectively) compared with healthy controls (both $\mathrm{p}<0.001$ ) and patients with inactive disease (both $\mathrm{p}<0.001$ ). The relation between disease activity and circulating sE-selectin was explored. In CD, there was a significant correlation between CDAI and circulating sE-selectin levels $(r=0.715, \mathrm{p}<0.001)$. Disease activity in UC was measured as mild, moderate, and severe using the Truelove and Witts' criteria. sE-selectin levels correlated well with disease activity.

\section{SCINTIGRAPHIC STUDIES}

Previous studies of patients with arthritis have shown that in the absence of active synovial inflammation, labelled anti-E-selectin antibody accumulates in bone marrow, liver, and spleen producing background similar to that seen in leucocyte scanning (fig 2). Excretion of radioparticles is also seen in the urinary bladder.

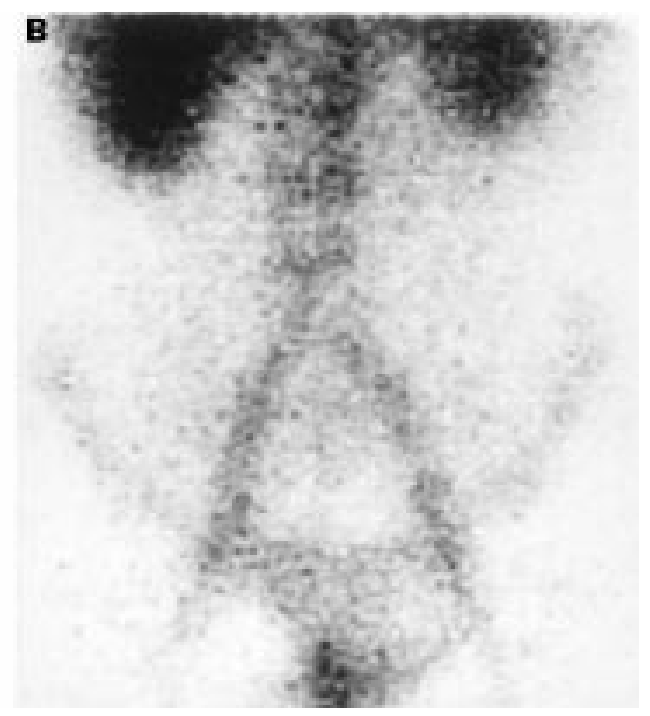



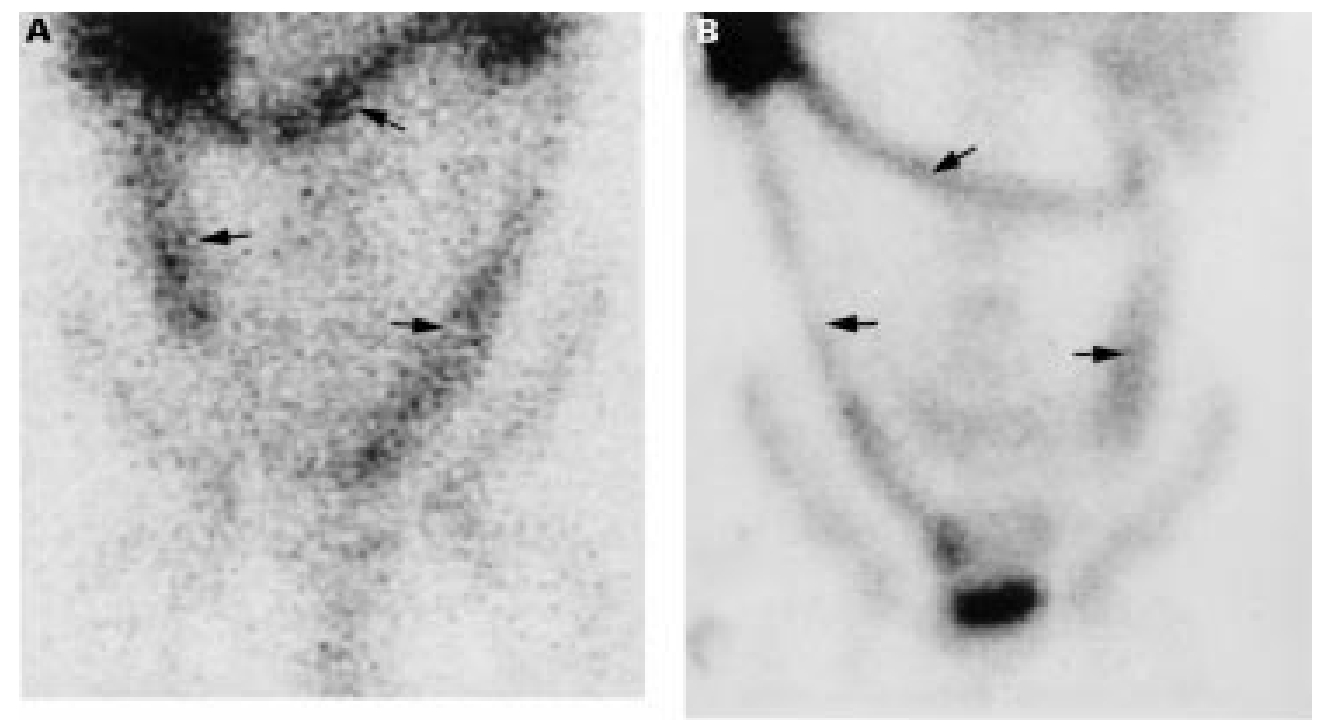

Figure 3 Images from a patient with pancolitis. (A) ${ }^{99 m}$ Tc leucocyte scan; (B) ${ }^{111}$ In labelled anti-E-selectin scan. Arrows indicate the areas of inflammation in the colon.

Seventeen patients with IBD were sequentially imaged with ${ }^{99 \mathrm{~m}} \mathrm{Tc}$ labelled leucocytes and 24 hours later with ${ }^{11}$ In labelled anti-E-selectin $\mathrm{F}\left(\mathrm{ab}^{\prime}\right)_{2}$ fragment (table 1). Twelve of these patients had areas of active inflammation detectable by leucocyte scanning, and 11 patients had anti-E-selectin scans in which abnormal localisation in areas of bowel was imaged (positive scans). Ten of the 13 patients with clinically active disease showed similar areas of disease isotope uptake with each type of scan (fig 3). One patient with a recent relapse of UC was positive with anti-E-selectin scanning alone, while two patients had positive leucocyte but negative anti-E-selectin scans. In four patients with clinically inactive disease, both types of scan were negative. Thus results were concordant for both detection and extent of inflammation in 10/13 patients with clinically active disease, and were also concordant in all four patients with inactive disease.
A major difference in the scan appearances with the two techniques concerned migration of radioactivity after initial localisation to bowel. As has been well recognised previously, labelled leucocytes are excreted into the intestinal lumen after initial localisation in the wall, and thereafter move distally with the faecal stream. This is known to render interpretation of the disease extent unreliable if scans are performed at time intervals of greater than four hours after reinjection of leucocytes (fig 4). In contrast areas identified by anti-E-selectin images stayed well localised in early and late scans and indeed were intensified further with time (fig 5).

Eight patients also underwent colonoscopic examination within two weeks prior to scanning although this was not a formal part of the study. This opportunity was taken to evaluate the results of anti-E-selectin scans and colonoscopic appearance. In all instances there was
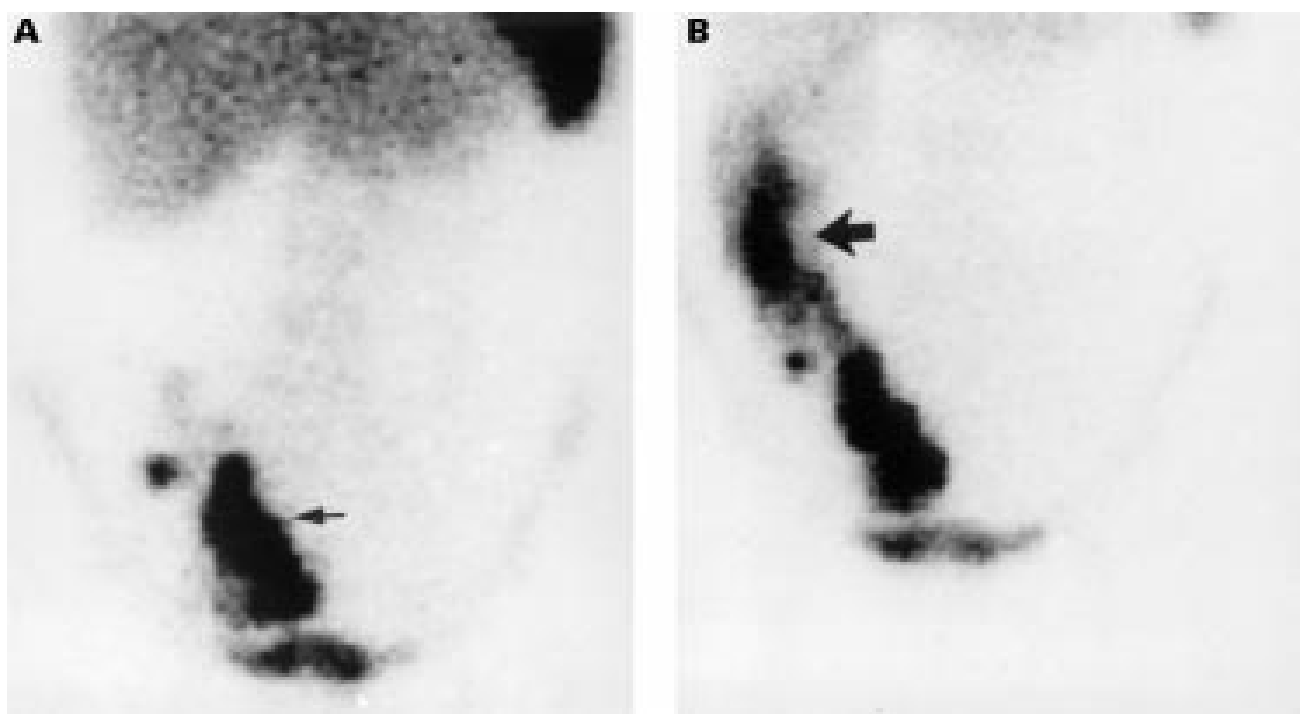

Figure $4{ }^{99 m}$ Tc labelled leucocyte images in a patient with Crohn's disease. (A) One hour image localises inflammation in terminal ileum and caecum. (B) At four hours, leucocytes have transmigrated (large arrow) into the bowel lumen making it difficult to estimate the true extent of disease. 
A

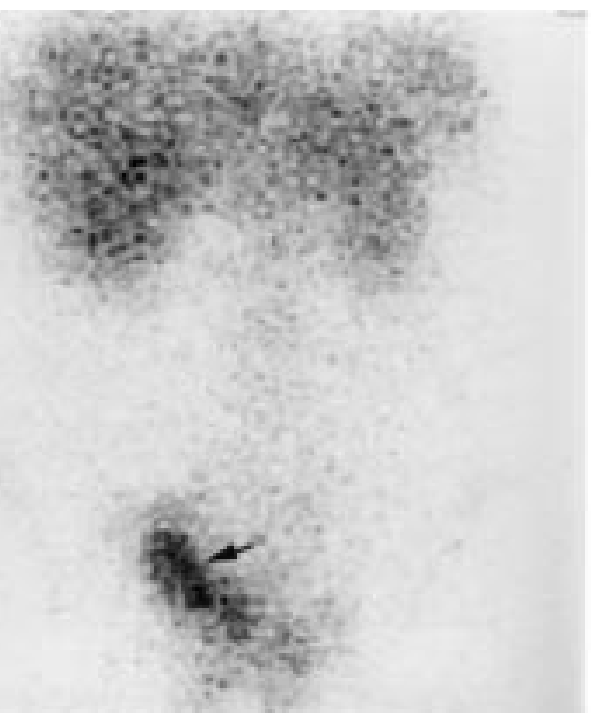

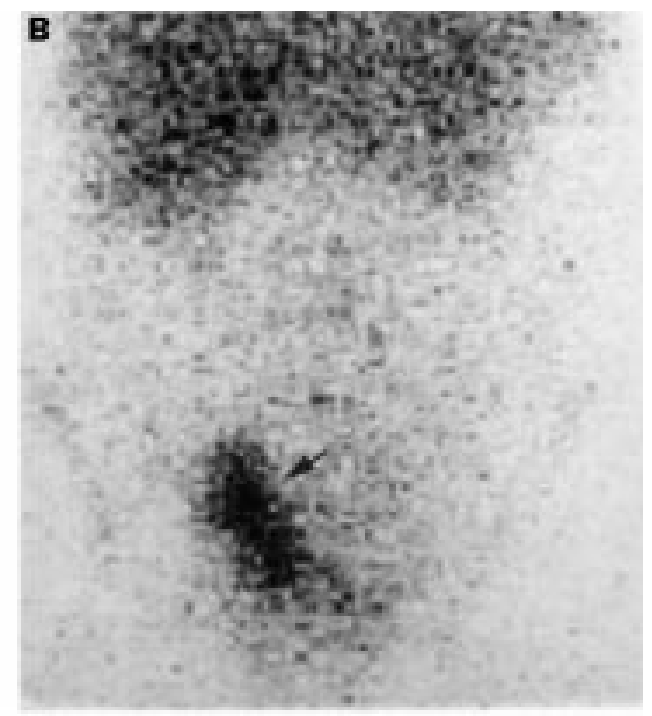

Figure $5{ }^{111}$ In labelled anti-E-selectin images in the same patient as in fig 4. Both four hour (A) and 24 hour (B) images localise inflammation in the same area. Arrows indicate areas of inflammation.

concordance between scans and colonoscopic appearance with respect to distribution of disease in the colon. In one patient in whom colonoscopic examination did not permit ileal examination, ileal inflammation was detected on the scan; in others more proximal areas of ileal inflammation were detected with the scan. Histological examination of the biopsy specimens of endoscopically active areas taken during colonoscopy confirmed the diagnosis of active inflammatory bowel disease. Table 2 summarises the results.

\section{IMMUNOHISTOLOGY}

Intestinal tissue specimens were obtained from five patients without inflammatory or neoplastic bowel disease, and from nine patients (four active and five inactive) with inflammatory bowel disease, five of whom also participated in the E-selectin imaging study. Of the imaged patients, three had clinically active disease and all were positive on E-selectin scan. Among these patients immunohistological examination of biopsy specimens, taken during colonoscopy or from surgically resected samples, showed strong widespread expression of E-selectin (fig 6). Two patients, who had clinically inactive disease at the time of imaging, were negative on scans and immunohistochemical examination of the tissue taken during colonoscopic examination showed weak or undetectable E-selectin expression. Table 3 presents the details of these five patients, together with the sE-selectin levels, and assessment of the degree of polymorphonuclear infiltration in the biopsy specimens. One patient with clinically active disease did not participate in the imaging study; however

Table 1 Patient characteristics

\begin{tabular}{|c|c|c|c|c|c|c|c|c|c|}
\hline $\begin{array}{l}\text { Patient } \\
\text { number }\end{array}$ & Diagnosis & $\begin{array}{l}\text { Clinical } \\
\text { activity }\end{array}$ & $\begin{array}{l}\text { Leucocyte } \\
\text { scan }\end{array}$ & Disease extent & $\begin{array}{l}\text { E-selectin } \\
\text { scan }\end{array}$ & Disease extent & $\begin{array}{l}\text { WBC } \\
\text { count }\end{array}$ & $E S R / C R P$ & Treatment \\
\hline 1 & $\mathrm{UC}$ & Severe & + & Pancolitis & + & Pancolitis & 18.2 & $126 / 110$ & $\begin{array}{l}\text { 5-ASA, prednisolone } \\
\text { (local + systemic) }\end{array}$ \\
\hline 2 & UC & Severe & + & Pancolitis & + & Pancolitis & 17 & $112 / 90$ & $\begin{array}{l}\text { 5-ASA, prednisolone } \\
\text { (local + systemic) }\end{array}$ \\
\hline 3 & UC & Severe & + & Transverse + descending colon & + & Transverse + descending colon & 16.4 & $98 / 102$ & $\begin{array}{l}\text { Sulphasalazine, } \\
\text { prednisolone, } \\
\text { azathioprine }\end{array}$ \\
\hline 4 & $\mathrm{UC}$ & Moderate & + & Descending + sigmoid colon & + & Descending + sigmoid colon & 13.4 & $87 / 83$ & $\begin{array}{l}\text { 5ASA + prednisolone } \\
\text { enema }\end{array}$ \\
\hline 5 & UC & Moderate & + & Sigmoid colon + rectum & + & Sigmoid colon + rectum & 11.9 & $57 / 42$ & $\begin{array}{l}\text { 5ASA + prednisolone } \\
\text { enema + oral } \\
\text { prednisolone }\end{array}$ \\
\hline 6 & $\mathrm{UC}$ & Moderate & + & Sigmoid colon & + & Sigmoid colon & 11.6 & $49 / 36$ & $5 \mathrm{ASA}+$ prednisolone \\
\hline 7 & UC & Mild & + & Sigmoid (a small segment) & - & & 11.6 & $32 / 21$ & $\begin{array}{l}\text { 5ASA + prednisolone } \\
\text { enema }\end{array}$ \\
\hline 8 & $\mathrm{UC}$ & Mild & - & & + & Rectum & 11.2 & $27 / 18$ & 5ASA \\
\hline 9 & UC & Inactive & - & & - & & 8.9 & $11 / 4$ & 5ASA \\
\hline 10 & UC & Inactive & - & & - & & 8.4 & $9 / 5$ & Sulphasalazine \\
\hline 1 & $\mathrm{CD}$ & $350^{\star}$ & + & Ileum (4 lesions) & + & Ileum (4 lesions) & 17.2 & $114 / 110$ & $\begin{array}{l}\text { 5-ASA, prednisolone, } \\
\text { azathioprine }\end{array}$ \\
\hline 2 & $\mathrm{CD}$ & $385^{\star}$ & + & Ileum (3 lesions) + caecum & + & Ileum (3 lesions) + caecum & 15.1 & $94 / 84$ & 5-ASA, prednisolone \\
\hline 3 & $\mathrm{CD}$ & $410^{\star}$ & + & Ileum (5 lesions) + caecum & + & Ileum (5 lesions) + caecum & 14.6 & $132 / 90$ & Prednisolone \\
\hline 4 & $\mathrm{CD}$ & $265^{\star}$ & + & Terminal ileum + caecum & + & Terminal ileum + caecum & 12.2 & $76 / 52$ & 5-ASA, prednisolone \\
\hline 5 & $\mathrm{CD}$ & $190^{\star}$ & + & Ileum (1 lesion) & - & & 11.1 & $27 / 32$ & Prednisolone \\
\hline 6 & $\mathrm{CD}$ & $80^{\star}$ & - & & - & & 8.1 & $14 / 8$ & No medication \\
\hline 7 & $\mathrm{CD}$ & $70^{\star}$ & - & & - & & 7.6 & $8 / 6$ & No medication \\
\hline
\end{tabular}

^ Disease activity measured by Crohn's Disease Activity Index.

UC, ulcerative colitis; CD, Crohn's disease; WBC, white blood cell; ESR, erythrocyte sedimentation rate; CRP, C-reactive protein; 5-ASA, 5-acetylsalicylic acid. 
Table 2 Histological and colonoscopic diagnosis, and E-selectin imaging

\begin{tabular}{lllll}
\hline $\begin{array}{l}\text { Patient } \\
\text { number }\end{array}$ & E-selectin scan (disease extent) & Colonoscopic distribution & Histology & $\begin{array}{c}\text { WBC } \\
\text { count }\end{array}$ \\
\hline 1 & Pancolitis & Pancolitis & Active UC & 17 \\
2 & Descending + sigmoid colon & Descending + sigmoid colon & Active UC & 13.4 \\
3 & Transverse, descending + sigmoid colon & Transverse, descending + sigmoid colon & Active UC & 11.9 \\
4 & Rectum & Rectum & Moderately active UC & 11.2 \\
5 & Nil & Nil & Inactive & 8.4 \\
6 & Ileum (3 lesions) + caecum & Terminal ileum + caecum & Active CD & 17.2 \\
7 & Ileum (5 lesions) + caecum & Terminal ileum + caecum & 14.6 \\
8 & Ileum & Could not reach & & 11.1 \\
\hline
\end{tabular}

UC, ulcerative colitis; CD, Crohn's disease; WBC, white blood cell.

immunohistochemical examination of biopsy specimens taken during colonoscopy showed widespread expression of E-selectin. Similarly three of five patients with clinically inactive disease, who did not participate in the imaging study, showed minimal or undetectable E-selectin expression on immunohistology. Thus of the nine patients studied immunohistologically, all four with active disease had E-selectin expression detected; of the five with clinically inactive disease, weak expression was detected in one. Four of five healthy volunteers had no E-selectin positive blood vessels and one had minimal labelling.
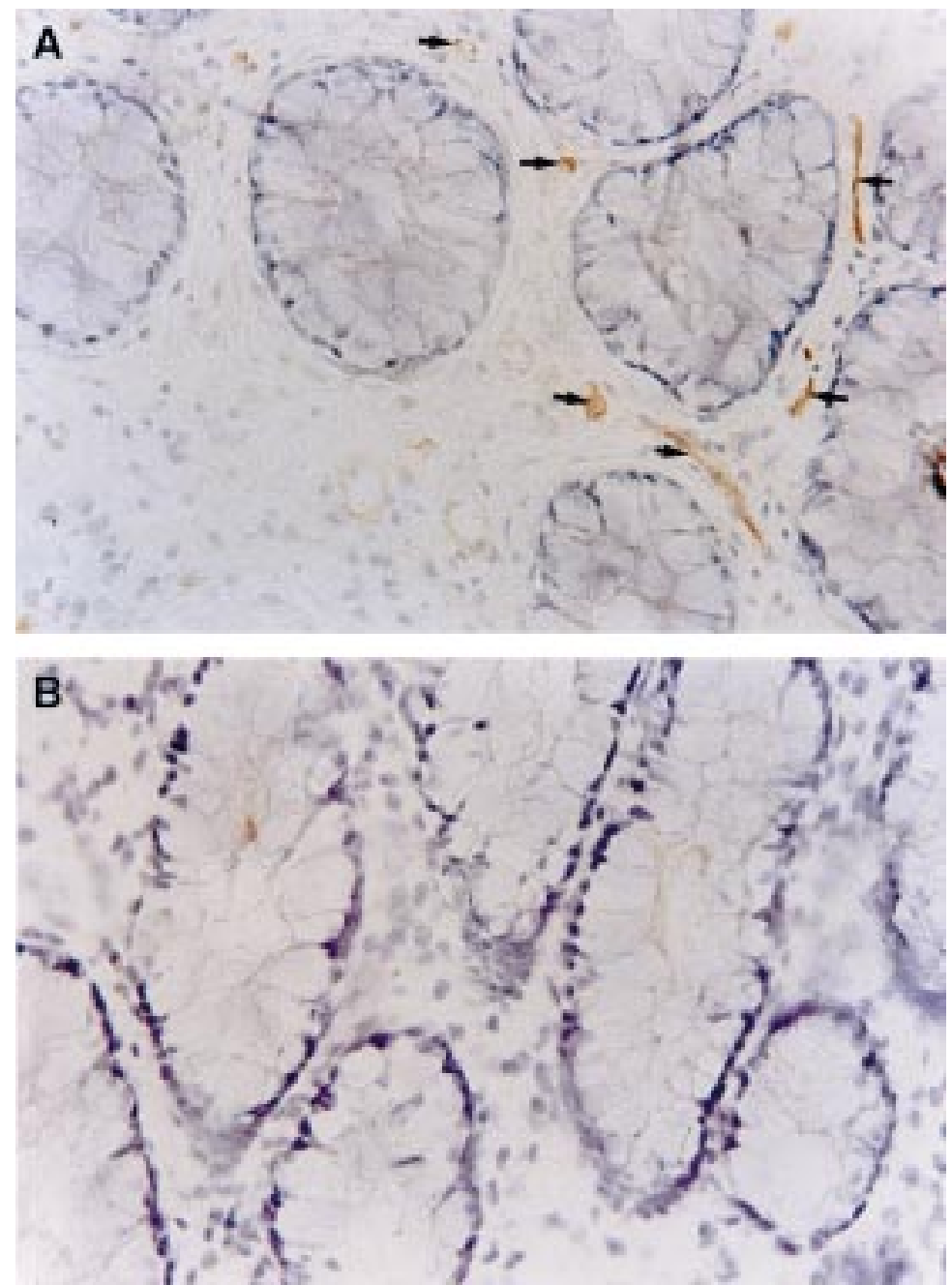

Figure 6 Colonic biopsy specimens from a patient with clinically active ulcerative colitis (A) and a control (B). Tissue section from a patient with UC shows strong widespread expression (+++) of E-selectin on vascular endothelium as indicated by arrows. Vascular endothelial E-selectin expression is absent in the colonic mucosa from the control (original magnification $\times 200$ ).

\section{Discussion}

There are well recognised problems in defining the extent and activity of IBD, especially in Crohn's disease. For example the rectum, which is the area of gut mucosa most readily available for inspection and sampling, may be endoscopically normal during relapse either due to the effects of local treatment in ulcerative colitis or disease distribution in Crohn's disease. Assessment of the whole colon in ulcerative colitis and Crohn's disease by colonoscopy and histology is often inadvisable in active disease and radiological examination of the small and large intestine may fail to reflect inflammatory activity.

The technique of leucocyte scanning was developed against this background, and in specialised centres has been shown to be effective in identifying the presence and site of active inflammation in IBD. ${ }^{24-27}$ Leucocyte scanning has also been developed for the quantitation of disease activity, and applied in clinical trials of drug and dietary therapy. Various authors have reported good correlation between the site and extent of labelled leucocyte accumulation and the results of endoscopy, histology, and radiology. ${ }^{28-31}$ However there are several disadvantages of leucocyte scanning techniques. The most obvious are the requirements for adequate numbers of circulating leucocytes and for in vitro manipulation of autologous blood with its associated risks of infection. The preparation of labelled leucocytes requires technical expertise, and this in particular seems to have limited the adoption of the technique beyond specialist centres. With respect to accuracy, a constraint of the use of leucocyte scanning in IBD is the fact that leucocytes that have migrated to inflamed bowel transmigrate into the intestinal lumen within a few hours, making the use of early scans essential to avoid overestimation of the extent of disease (fig 4). In addition, if the readily available ${ }^{99 \mathrm{~m}} \mathrm{Tc}$ HMPAO technique is used to label leucocytes, urinary excretion of isotope into the bladder renders assessment of the pelvis more difficult and biliary excretion contributes to the appearance of bowel radioactivity in delayed views.

Despite these shortcomings many specialist centres have recognised leucocyte scanning as a reliable technique for the diagnosis and assessment of inflammatory bowel disease, but a simpler alternative technique is clearly desirable. This study was designed to explore an approach which does not require in vitro manipulation of autologous blood, is neither technically demanding nor time consuming, 
Table 3 Detailed results of five patients with E-selectin and leucocyte scans, colonic histology and sE-selectin concentrations

\begin{tabular}{|c|c|c|c|c|c|}
\hline & \multicolumn{3}{|c|}{ Clinically active } & \multicolumn{2}{|c|}{ Clinically inactive } \\
\hline & Patient 1 & Patient 2 & Patient 3 & Patient 4 & Patient 5 \\
\hline Diagnosis & UC & UC & $\mathrm{CD}$ & UC & $\mathrm{CD}$ \\
\hline E-selectin scan & + & + & + & - & - \\
\hline Leucocyte scan & + & + & + & - & - \\
\hline E-selectin expression & +++ & +++ & ++ & - & \pm \\
\hline PMN infiltration & +++ & ++ & ++ & - & \pm \\
\hline $\mathrm{sE}$-selectin $(\mathrm{ng} / \mathrm{ml})$ & 129 & 122 & 137 & 25 & 41 \\
\hline
\end{tabular}

PNM, polymorphonuclear cells; sE-selectin, soluble circulating E-selectin.

and which could be available to non-specialist centres. Previous approaches aimed at simplifying scintigraphic techniques have included the use of labelled antigranulocyte monoclonal antibody, chemotactic peptides, simple colloids phagocytosed by leucocytes, and human immunoglobulin. ${ }^{32-36}$ Unfortunately none of these agents has fulfilled their early promise, either due to insufficient selective uptake into inflammatory sites or problems with nonspecific binding, but the data presented here show that antibody scanning for E-selectin offers a convenient and effective approach.

E-selectin provides an attractive target for imaging inflammation in IBD. The molecule, on the endothelial surface of blood vessels, is reliably detected by monoclonal antibody. E-selectin is up regulated during inflammation and its expression is thought to reflect the effects of proinflammatory cytokines (for example, IL-1 or TNF), or possibly bacterial lipopolysaccharide, on the activation state of endothelial cells. The inflamed mucosa in IBD has been shown to express IL- 1 and TNF- $\alpha$ by multiple techniques including immunohistochemistry. ${ }^{2-4}$ We have shown that enhanced E-selectin expression in IBD can be localised by radiolabelled antibody scanning, and that the results show good concordance with scans obtained with labelled leucocytes. This concordance was apparent both for patients with colonic and for those with small intestinal disease. In a limited analysis of regional E-selectin expression detected by scintigraphy with regional colonoscopic appearances, good correlation was also found. At this stage, we have not performed a series of studies in other inflammatory diseases of the bowel such as bacillary dysentery or diverticulitis. There is however no reason to anticipate that the up-regulation of E-selectin in the bowel should be limited to the chronic idiopathic inflammatory bowel diseases that we have studied; indeed in one individual with HIV associated diarrhoea in whom the technique was applied, notable terminal ileal accumulation of anti-E-selectin was identified, and a diagnosis of cytomegalovirus infection and cryptosporidiosis eventually established. The study in this individual also exemplifies one potential advantage of monoclonal antibody scintigraphy as compared with leucocyte scanning: avoidance of ex vivo manipulation of blood from potentially infectious patients.

In this study the anti-E-selectin monoclonal antibody was labelled with ${ }^{111}$ In in order to allow comparison within 24 hours with ${ }^{99 \mathrm{~m}} \mathrm{Tc}$ labelled leucocyte scans; preliminary observations indicate that more focal and intense images of anti-E-selectin localisation can, as would be expected, be obtained using ${ }^{99 \mathrm{~m}} \mathrm{Tc}$ labelling and we are currently developing this aspect further. It is also clear that before the technique will be widely used, further developments of monoclonal technology are desirable. Although murine antibodies can be safely administered, particularly as antibody fragments when unbound antibody can be excreted rapidly, the use of humanised or chimeric antibodies minimises further the risk of an untoward immunological reaction.

Expression of E-selectin in active IBD was not only shown locally in inflamed tissues, but was also increased in plasma in the form of the circulating soluble molecule (sE-selectin). While the majority of endothelial cell surface E-selectin is thought to be removed from the cell surface by internalisation, a proportion is shed and this probably accounts for the circulating soluble form. ${ }^{37}$ It is of interest that levels of sE-selectin were significantly increased in active IBD, and it is possible that sE-selectin measurements might be useful clinically in IBD for long term monitoring. Some studies have not found a difference in soluble E-selectin levels among patients with active disease as compared with those with inactive or no disease, ${ }^{38}$ but more recent studies report the same findings as our study. ${ }^{39}{ }^{40}$ It may be that measuring circulating sE-selectin could be used for planning investigations in patients with inflammatory bowel disease and to determine when anti-E-selectin scanning will be useful in the assessment of disease, a hypothesis which requires further evaluation. The demonstration of vascular endothelial E-selectin expression in active disease immunohistochemically, with absent or weak expression in inactive disease and healthy volunteers, suggests that E-selectin is an attractive candidate for further development in the diagnosis and treatment of inflammatory processes; there are currently no data as to whether alternative vascular cell adhesion molecules (VCAM) could be developed as targets in a similar way. Both VCAM-1 and intercellular adhesion molecule (ICAM) 1 may have a degree of constitutive expression in normal mucosa, and VCAM-1 may not be overexpressed in inflammatory bowel disease. ${ }^{39}$

In conclusion, we have shown the feasibility of using anti-E-selectin monoclonal antibody to evaluate patients with IBD. This imaging technique has a number of advantages over radiolabelled leucocyte scanning, and further work is in progress towards developing the technique for general use. We anticipate that the use of ${ }^{99 \mathrm{~m}} \mathrm{Tc}$ labelled anti-E-selectin antibody will improve image quality in comparison with ${ }^{111} \mathrm{In}$. With further study, the analysis of scans should allow quantitation of E-selectin expression, by expressing regional uptake as a proportion of injected dose, or by comparison of gut uptake with another region of uptake such as bone marrow. Besides the importance of the study for the identification of inflammatory activity in IBD, this report also paves the way towards the potential use of antibodies to adhesion 
molecules for therapeutic purposes. A recent study has shown improvement in acetic acid induced inflammatory bowel disease in rats after administration of anti-ICAM-1 antibodies. ${ }^{41}$ Targeting antibody to adhesion molecules in inflamed endothelium in man has been shown in our study to be feasible, and the strategy can in the future be developed to address combinations of antigen and antibody aimed at preventing leucocyte accumulation.

This work was supported by the National Association for Colitis and Crohn's Disease UK, the Hammersmith Hospitals Trust Special Trustees, and the Medical Research Council of the UK

1 Pober JS, Cotran RS. Cytokines and endothelial cell biology. Physiol Rev 1990;70:427-51.

2 Butcher EC. Leukocyte-endothelial cell recognition: three (or more) steps to specificity and diversity. Cell 1991;67: 1033-6.

3 Bevilacqua MP, Nelson RM. Selectins. I Clin Invest 1993;91:379-87.

4 Springer TA. Traffic signals for lymphocyte recirculation and leukocyte emigration: the multistep paradigm. Cell and leukocyte emig

5 Ohtani H, Nakamura S, Watanabe Y, et al. Light and electron microsopic immunolocalization of endothelial leukocyte adhesion molecule-1 in inflammatory bowel disease. Morphological evidence of active synthesis and secretion into vascular endothelium. Virchows Arch 1992;420:403-9.

6 Koizumi M, King N, Lobb R, et al. Expression of vascular adhesion molecules in inflammatory bowel disease. Gastroenterology 1992;103:840-7.

7 Bloom S, Simmons D, Jewell DP. Adhesion molecules intercellular adhesion molecule-1 (ICAM-1), ICAM-3 and B7 are not expressed by epithelium in normal or inflamed gut. Clin Exp Immunol 1995;101:L157-63.

8 Oshitani N, Campbell A, Bloom S, et al. Adhesion molecule expression on vascular endothelium and nitroblue tetrazolium reducing activity in human colonic mucosa. Scand $\mathcal{f}$ Gastroenterol 1995;30:915-20.

9 Cotran RS, Gimbrone MA Jr, Bevilacqua MP, et al. Induction and detection of a human endothelial activation tion and detection of a human endothe

10 Norris P, Poston RN, Thomas DS, et al. The expression of endothelial leukocyte adhesion molecule-1 (ELAM-1), endothelial leukocyte adhesion molecule-1 (ELAM-1), intercellular adhesion molecule-1 (ICAM-1), and vascular cell adhesion molecule-1 (VCAM-1) in experimental cutaerythema and delayed hypersensitivity. F Invest Dermatol 1991;96:763-70.

11 Keelan ETM, Licence ST, Binns RM, et al. Characterization of E-selectin expression in vivo using a radiolabelled monoclonal antibody. Am $\mathcal{7}$ Physiol 1994;266: H279-90.

12 Binns RM, Licence ST, Harrison AA, et al. In vivo E-selectin upregulation correlates with early infiltration of PMN, later with PBL-entry: mAb blocks both. Am 7 Physiol 1996;270:H183-93.

13 Keelan ETM, Harrison AA, Chapman PT, et al. Imaging vascular endothelial activation: an approach using radiolabelled monoclonal antibody a

adhesion molecule E-selectin. $\mathcal{F}$ Nucl Med 1994;35:276-81.
Chapman PT, Jamar F, Harrison AA, et al. Noninvasive

Chapman PT, Jamar F, Harrison AA, et al. Noninvasive imaging of E-selectin expression by activated endothelium in urate $1752-6$.

15 Jamar F, Chapman PT, Harrison AA, et al. Inflammatory arhritis: imaging of endothelial activation with indium-111labelled $\mathrm{F}(\mathrm{ab})_{2}^{\prime}$ fragment of anti-E-selectin monoclonal antibody. Radiology 1995;194:843-50.

16 Chapman PT, Jamar F, Keelan ETM, et al. Imaging endothelial activation in rheumatoid arthritis using a radiolabelled monoclonal antibody against E-selectin. Arthritis Rheum 1996;39:1317-75.

17 Gearing AJH, Newman W. Circulating adhesion molecules in disease. Immunol Today 1993;14:506-12.

18 Montefort S, Lai CK, Hapahi P, et al. Circulating adhesion molecules in asthma. Am f Respir Crit Care Med 1994;149: $1149-52$.
19 Best WR, Becktel JM, Singleton JW, et al. Development of a Crohn's disease activity index: National Cooperative Crohn's Disease study. Gastroenterology 1976;70:439-44.

20 Truelove SC, Witts LJ. Cortisone in ulcerative colitis: final report on a therapeutic trial. BMF 1955;30:354-6.

21 Wellicome SM, Thornhill $\mathrm{MH}$, Pitzalis C, et al. A monoclonal antibody that detects a novel antigen on endothelial cells that is induced by tumour necrosis factor, IL-1 or lipopolysaccharide. 7 Immunol 1990;144:2558-65.

22 Danpure HJ, Osman S, Carroll MJ. The development of a clinical protocol for the radiolabelling of mixed leucocytes with $99 \mathrm{Tcm}-$ hexamethylpropyleneamine oxime. Nucl Med Commun 1988;9:465-75.

23 Cashman SJ, Pusey CD, Evans DJ. Extraglomerular distribution of immunoreactive Goodpasture antigen. $\mathcal{F}$ Pathol 1988;155:61-70.

24 Rothkotter HJ, Ulbrich H, Pabst R. The postnatal development of gut lamina propria lymphocytes: number, proliferation, and $\mathrm{T}$ and $\mathrm{B}$ cell subsets in conventional and germ-free pigs. Pediatr Res 1991;29:237-42.

25 Scholmerich J, Schmidt E, Schumichen C, et al. Scintigraphic assessment of bowel involvement and disease activity in Crohn's disease using technetium 99m-hexamethyl propylene amine oxine as leukocyte label. Gastroenterology 1988;95:1287-93.

26 Roddie ME, Peters AM, Danpure HJ, et al. Inflammation: imaging with Tc-99m HMPAO-labelled leukocytes. Radiology 1988;166:767-72

27 Peters AM, Danpure HJ, Osman S, et al. Clinical experience with $99 \mathrm{mTc}$-hexamethylpropylene-amineoxime for labelling leucocytes and imaging inflammation. Lancet 1986;ii: 946-9.

28 Arndt JW, van der Sluys Veer A, Blok D, et al. Prospective comparative study of technetium-99m-WBCs and indium111-granulocytes for the examination of patients with inflammatory bowel disease. $7 \mathrm{Nucl} \mathrm{Med} \mathrm{1993;34:1052-7.}$

29 Allan RA, Sladen GE, Bassingham S, et al. Comparison of simultaneous $99 \mathrm{mT}$ c-HMPAO and 111-In oxine labelled white cell scans in the assessment of inflammatory bowel disease. Eur F Nucl Med 1993;20:195-200.

30 Costa DC, Lui D, Ell PJ. White cells radiolabelled with In-111 and Tc-99m-a study of relative sensitivity and in vivo viability. Nucl Med Commun 1988;9:725-31.

31 Saverymuttu SH, Camilleri $\mathrm{M}$, Rees $\mathrm{H}$, et al. Indium 111-granulocyte scanning in the assessment of disease extent and disease activity in inflammatory bowel disease. A comparison with colonoscopy, histology, and fecal indium 111-granulocyte excretion. Gastroenterology 1986; 90:1121-8.

32 Becker W, Bair J, Behr T, et al. Detection of soft tissue infections and osteomyelitis using a technetium- $99 \mathrm{~m}$ labeled antigranulocyte monoclonal antibody fragment. $7 \mathrm{Nucl}$ Med 1994;35:1436-43.

33 Fischman AJ, Babich JW, Rubin RH. Infection imaging with technetium-99m-labeled chemotactic peptide analogs. Semin Nucl Med 1994;24:154-68.

34 Fischman AJ, Rubin RH, Khaw BA, et al. Detection of acute inflammation with indium-111 labelled nonspecific polyclonal IgG. Semin Nucl Med 1988;18:344-55

35 Rubin RH, Fischman AJ, Callahan RJ, et al. Indium-111labeled nonspecific immunoglobulin scanning in the detection of focal infection. N Engl f Med 1989;321:935-40.

36 Mairal L, de Lima PA, Martin-Comin J, et al. Simultaneous administration of 111-In-human immunoglobulin and $99 \mathrm{~m}-\mathrm{Tc}-\mathrm{HMPAO}$ labelled leucocytes in inflammatory bowel disease. Eur F Nucl Med 1995;22:664-70.

37 von Asmuth EJU, Smeets EF, Ginsel LA, et al. Evidence for endocytosis of E-selectin in human endothelial cells. Eur 7 Immunol 1992;22:2519-26.

38 Jones SC, Banks RE, Haidar A, et al. Adhesion molecules in inflammatory bowel disease. Gut 1995;36:724-30.

39 Patel RT, Pall AA, Keighley MR. Circulating soluble adhesion molecules in inflammatory bowel disease. Eur 7 Gastroenterol Hepatol 1995;7:1037-41.

40 Nielsen OH, Brynskov J, Vainer B. Increased mucosal concentrations of soluble intracellular adhesion molecule-1 (sICAM-1), sE-selectin, and interleukin-8 in active ulcerative colitis. Dig Dis Sci 1996;9:1780-5.

41 Wong PY, Yue G, Yin K, et al. Antibodies to ICAM-1 amelorate inflammation in acetic acid induced inflammatory bowel disease. Adv Prostaglandin Thromboxane Leukot Res 1995;23:337-9. 